\title{
Influence of Hole-Making Procedures on Fatigue Behaviour of High Strength Steel Plates
}

\author{
C. Jiménez-Peña ${ }^{1, *}$, C. Goulas ${ }^{2,3}$, \\ B. Rossi ${ }^{4}$ \\ D. Debruyne ${ }^{1}$ \\ 1 KU Leuven, Department of Metallurgy and Materials Engineering, Kasteelpark Arenberg 44, 3001 Leuven, Belgium \\ 2 Delft University of Technology, Department of Materials Science and Engineering, Mekelweg 2 2628CD Delft, The \\ Netherlands \\ 3 Rotterdam Fieldlab Additive Manufacturing (RAMLAB), Scheepsbouwweg 8 8089JW Rotterdam, The Netherlands \\ 4 KU Leuven, Department of Civil Engineering, Kasteelpark Arenberg 40, 3001 Leuven, Belgium \\ * Correspondence: carlos.jimenezpena@kuleuven.be; Tel.: +32-465-593-138
}

\section{Abstract}

High strength steels (HSS) offer a unique opportunity to reduce the weight of civil and off-shore structures and heavy-duty machinery. Such equipment is subjected to continuous cyclic loading and therefore fatigue failure often happens where concentrations of stresses are present, the latter most of the time being caused by connection details. Previous studies have demonstrated that an increase in yield strength does not lead to a proportional increase in fatigue resistance, particularly in welded connections. In that regard, the utilisation of bolted joints is often proposed as an alternative to welded joints. The hole-making procedure is an essential factor in the assessment of the fatigue resistance of bolted joints, since different hole-making techniques yield different surface qualities and residual stresses, which consequently impact the final fatigue limit. This work addresses the effect of the main mechanical (punching, drilling and waterjet) and thermal (plasma and laser) cutting techniques on the fatigue performance of HSS plates containing holes.

A series of fatigue tests with moderately thick plates made of S500MC were carried out using different hole-making techniques. The surface, geometry and residual damage of every hole-making procedure were studied by means of optical evaluation, hardness tests and roughness evaluation, and large differences were observed: drilling was found to produce the most geometrically accurate hole and the smoothest surface finish; while laser and waterjet cutting displayed the best fatigue 
performance. The results of this research can provide an estimation of the applicability of each holemaking process to this particular HSS grade.

Keywords: Fatigue; High Strength Steel; Hole; Cutting; Bolted joints

Declaration of interests: This work was supported by the European Research Project DURAMECH: "Towards Best Practice for Bolted Connections in High Strength Steels" [project number 709962 (2016)]. The funding source had no involvement in the study design; in the collection, analysis and interpretation of data; in the writing of the report; and in the decision to submit this article for publication.

\section{Introduction}

The application of High Strength Steels (HSS) in mechanical structures has been gaining popularity because lighter frame designs are possible without compromising the safety or structural requirements. HSS are implemented in numerous engineering applications, ranging from civil and offshore structures up to heavy duty machinery. Jensen and Bloomstine [1] and Miki et. al [2] reported the increased utilisation of HSS on steel bridges in the last decade, which allows for minimized weight and construction costs [3]. Offshore structural applications also benefit from the use of HSS since they offer a number of advantages over conventional steels, particularly where weight is important $[4,5]$. In offshore wind towers, for example, HSS allow for taller tower hub heights [6] that make greater use of higher wind speeds. Takahashi [7] and Zhang et. al. [8] also introduced examples in the automotive sector, where parts (reinforcements, chassis, bumpers, etc.) made in mild steel were replaced with HSS. The implementation of HSS in mobile structures in specially significant from an ecological point of view as lighter vehicles result in decreased fuel consumption and greenhouse gas emissions, but also in increased payload. The overall superior performance of HSS often compensates for its higher manufacturing costs as explained by Sperle [9].

Many of the aforementioned applications usually undergo continuous, cyclic loading, which makes them prone to fatigue failure. Examples of this are the variable loads produced by the passing of 
vehicles on a bridge or the propeller movement in a wind tower. Consequently, the fatigue resistance of HSS has attracted attention. Fatigue performance is particularly crucial at the level of details because, at these locations, the geometry is often such that high concentration of stresses develop.

Welded steel joints are typical connections used in civil and mobile structures. They provide an efficient method of creating structures of medium complexity consisting of standard sub-components with simple geometry, like plated or hollow sections. Over the last decades, significant efforts have been made to improve the fatigue performance of welded steel components. But it is well known that the fatigue performance of steel components in the as-welded condition does not substantially increase when increasing the yield or tensile strength of the base metal [10]. Furthermore, since the weldability of HSS is lower than that of mild steels [11, 12], residual stresses and uneven cooling appears to be more detrimental for structural integrity than in mild steel [13-16].Consequently, the use of very high strength grades, with yield strengths above $690 \mathrm{MPa}$, in civil and mechanical engineering structures is relatively uncommon especially because of restrictive design rules and welding problems. Since welded connections are one of the most used joining techniques in structural applications, numerous studies have focused on the problem of the fatigue resistance of welds made of HSS and related improvement techniques. In the study performed by Y1ldırım [17], over 1500 fatigue data points extracted from numerous literature sources were evaluated for two of the most common weld fatigue strength improvement techniques: high frequency mechanical impact treatment and tungsten inert gas dressing. The primary conclusion of these investigations is that the susceptibility of HSS to weld defects requires particular post-weld treatments to achieve a satisfactory fatigue resistance. Similar conclusions were drawn in the European Research project FATWELD [18]. Adding such a step in the manufacturing process substantially complicates the production lines and is usually not preferred. Therefore, employing alternative joining techniques, such as bolted connections, is often seen as a good alternative to avoid these difficulties. 
Bolted connections in HSS have received considerable attention in recent years and numerous studies concerning the static strength of bolted joints in HSS have been conducted [19-22]. The quantity of literature regarding fatigue performance of bolted connections in HSS is, however, limited. Hämäläinen and Björk [23] compared the fatigue performance of double-lap bolted connections in structural steel S355 and HSS S960QC and reported the sensitivity of the latter to fretting fatigue failure. In a previous work by the authors [24] the influence of pre-tension force on the overall fatigue performance of single-lap bolted connections made of S500MC was investigated. Results showed that pre-tension affected the fretting fatigue behaviour of the parts in contact and that greater pretension levels resulted in improved fatigue performance.

Additional parameters in the bolted connection, such as the hole-making process, could affect the fatigue behaviour as well. One of the essential requirements in bolted joint is the existence of a hole within the joined parts to allocate the fastening elements. For this purpose, a wide range of holemaking processes are employed in industrial applications: punching, drilling, plasma-cutting, waterjet, laser-cut; and the final process choice depends on the application and on factors such as reaching an acceptable cost, the microstructure of the material and the thickness of the plate to be perforated.

Each cutting technique results in a characteristic surface condition and residual stress state around the hole, which has been the topic of reference research. Brown et. al. [25] performed a comparative study between punching and drilling methods for structural steel plates (A36, A572 Grade 50 and High Carbon Grade 55) subjected to fatigue loading. Plates with punched holes exhibited not only lower static strength and ductility than plates with drilled holes, but also reduced fatigue performance. Similar research was performed by Garcia et. al. [26] for plates made of S355M with holes cut by plasma, laser and oxy-fuel. Results indicated a significant influence of the cutting method on both crack initiation and fatigue life, with oxy-fuel cutting exhibiting the best fatigue performance. Valtinat and Huhn [27] investigated punched holes for both flat plane specimens and bolted connections made of S 235 JR G2 subjected to fatigue loading. The authors stated that the punching process dramatically 
reduced the fatigue life, except when pre-tensioned bolts were employed. The pre-tension load creates a high-pressure region under the washers that offers a certain protection to the surface around the hole and, therefore, the hole quality did not affect fatigue. A similar behaviour was reported by Brown, Lubitz [25] where pre-tensioned bolts were utilized. For non-pre-tensioned bolts, however, the hole manufacturing method has been found to influence the fatigue performance [28]. Still, most published research focuses on milder steel grades and may not be applicable to HSS grades that are currently utilized. In general, HSS have low formability [10] which may result in distortions and large presence of singular defects during mechanical hole-making processes such as punching. Thermal cutting processes, such as laser-cut, might also be limited due to the lower weldability of HSS. The imperfections induced by the hole-making procedures in the surface of the hole and its surroundings are likely to affect fatigue performance and they will definitely restrict its application to certain application where strict geometrical tolerances are required. An extensive study considering both thermal and mechanical processes, fatigue behaviour and microstructural characterization in HSS, to the best of the knowledge of the authors, is not available in the existing literature. The objective of the present research is to gain deep understanding on the mechanism of hole-making processes and to assess its effect when applied to moderately thick HSS grades. In this article, the effect of the most common hole-making processes, mechanical and thermal, on the fatigue behaviour of the HSS grade S500MC is reported. In order to study the effect of the cutting process exclusively, the other parameters of the bolted connections were not considered. Uniaxial cyclic tests were performed on samples with a centred hole that simulates the presence of a bolt hole in a real component. The quality of the produced hole is assessed by optical evaluation, hardness tests and roughness evaluation. The fatigue performance of the tested samples is then compared. The fractured surfaces are analysed by optical and electron microscopy. 


\section{Methods}

\subsection{Material}

An often used HSS grade was considered in this investigation, S500MC, supplied in rolled plates of $1500 \mathrm{~mm} \times 1000 \mathrm{~mm} \times 6 \mathrm{~mm}$. The steel grade is a thermo-mechanically rolled (M) structural steel (S) with an specified minimum yield strength at ambient temperature of $500 \mathrm{MPa}$ suitable for cold forming (C) [29]. The mill-certificate chemical composition of the steel as provided by the manufacturers in [30] is summarized in Table 1. The mechanical properties of the steel were measured in a related work package within the same European Research project [31]. Three static uniaxial tests were performed in the rolling direction while the averaged strain in the central region of the sample was extracted with Digital Image Correlation. The employed procedure is partly described in [32].

Table 1. Chemical composition and mechanical properties of HSS grade S500C.

\begin{tabular}{|c|c|c|c|c|c|c|c|c|c|c|c|}
\hline \multicolumn{12}{|c|}{ Chemical composition (wt.\%) } \\
\hline & $\mathrm{C}$ & $\mathrm{Si}$ & $\mathrm{Mn}$ & $\mathrm{P}$ & $\mathrm{S}$ & $\mathrm{Al}$ & $\mathrm{Nb}$ & $\mathrm{V}$ & $\mathrm{Ti}$ & Mo & $\mathrm{B}$ \\
\hline \multirow{2}{*}{ S500MC } & $\leq$ & $\leq$ & $\leq$ & $\leq$ & $\leq$ & \multirow{2}{*}{0.015} & $\leq$ & $\leq$ & $\leq$ & \multirow{2}{*}{ - } & \multirow{2}{*}{ - } \\
\hline & 0.120 & 0.500 & 1.700 & 0.025 & 0.015 & & 0.090 & 0.200 & 0.150 & & \\
\hline \multicolumn{12}{|c|}{ Mechanical properties } \\
\hline & \multicolumn{2}{|c|}{$\begin{array}{c}\text { Young modulus } \\
(\mathrm{GPa})\end{array}$} & \multicolumn{3}{|c|}{ Yield stress (MPa) } & \multicolumn{2}{|c|}{ UTS (MPa) } & \multicolumn{2}{|c|}{ Elongation (\%) } & \multicolumn{2}{|c|}{$\begin{array}{c}\text { Hardness } \\
\text { (HV0.2) }\end{array}$} \\
\hline S500MC & \multicolumn{2}{|c|}{210} & \multicolumn{3}{|c|}{$562 \pm 6$} & \multicolumn{2}{|l|}{$658 \pm 4$} & \multicolumn{2}{|c|}{$13.7 \pm 1.2$} & \multicolumn{2}{|c|}{$207 \pm 7$} \\
\hline
\end{tabular}

\subsection{Sample design}

The samples were designed with the aim of isolating the effect of the hole-making process from the other parameters governing the behaviour of bolted connections, such as the bolt preload and the washer geometry. Therefore, the sample employed herein consists of a dog bone specimen with a hole in its centre. The dimensions of this sample can be found in Figure 1. The hole diameter was designed to allocate an M16 bolt. The distance from the hole centre to the outer edges is 1.5 times the 
hole diameter, as specified in the EC3-1-8 for bolted connections under cyclic loading [33]. The same design value was employed by Sánchez et. al. [34] and Garcia et. al. [35] for similar studies with punched and thermally cut holes, respectively. The radius of the clamping area and its distance to the central hole were selected after a parametric finite element (FE) study to ensure that the stress state near the hole remained unaffected.

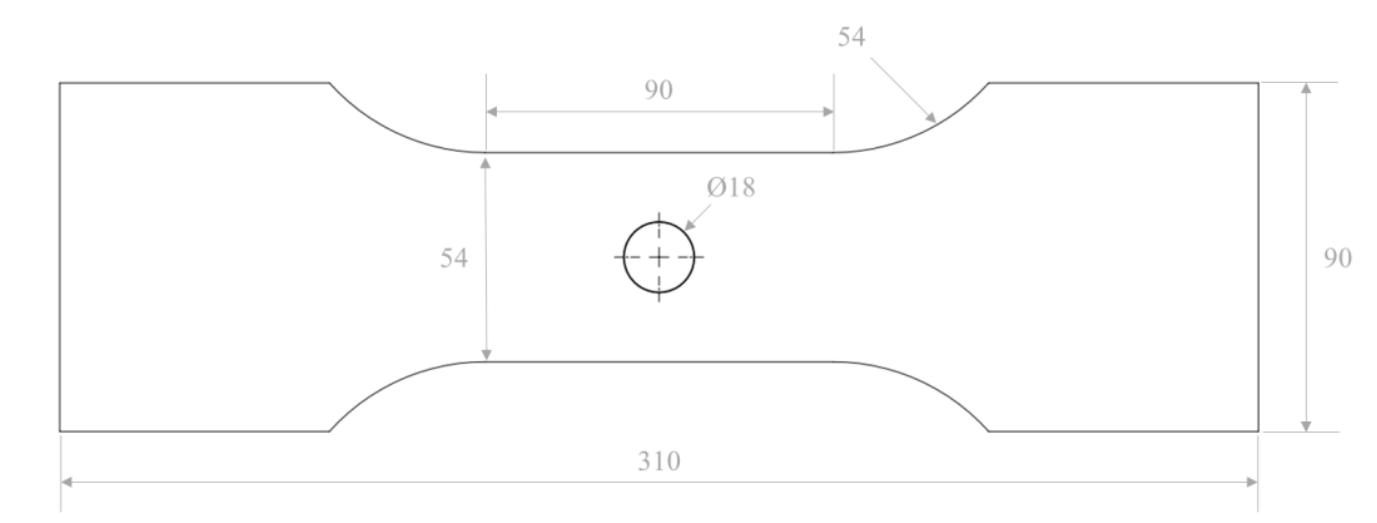

Figure 1. Sample design. Units in mm.

\subsection{Microstructural characterization and fractography}

The material was evaluated by means of light optical microscopy (LOM) and Scanning-Electron Microscopy (SEM). For LOM, a VHX 5000 Keyence digital microscope was used equipped with image analysis software. The characterisation with SEM was performed using a JEOL JSM-6500F operated at $15 \mathrm{KV}$. The samples for microstructural evaluation were prepared following standard metallographic preparation procedures and were etched with Nital 2\% (98\% Ethanol and 2\% $\left.\mathrm{HNO}_{3}\right)$. The fracture surfaces were immersed with acetone in an ultrasonic bath to remove artefacts. 


\subsection{Hole-making procedures}

The holes in the test specimens were produced by seven distinct hole-making procedures using five different machining techniques: punching (three conditions), drilling, water-jet cutting, laser cutting and plasma cutting. The optimal parameters for each cutting procedure were based on industry daily practice - provided to the authors by several companies - to achieve the best possible hole quality for all cutting methods. An overview of all the hole-making conditions is provided in Figure 2 while the main cutting parameters for each technique are summarized in Tables 2 to 6.

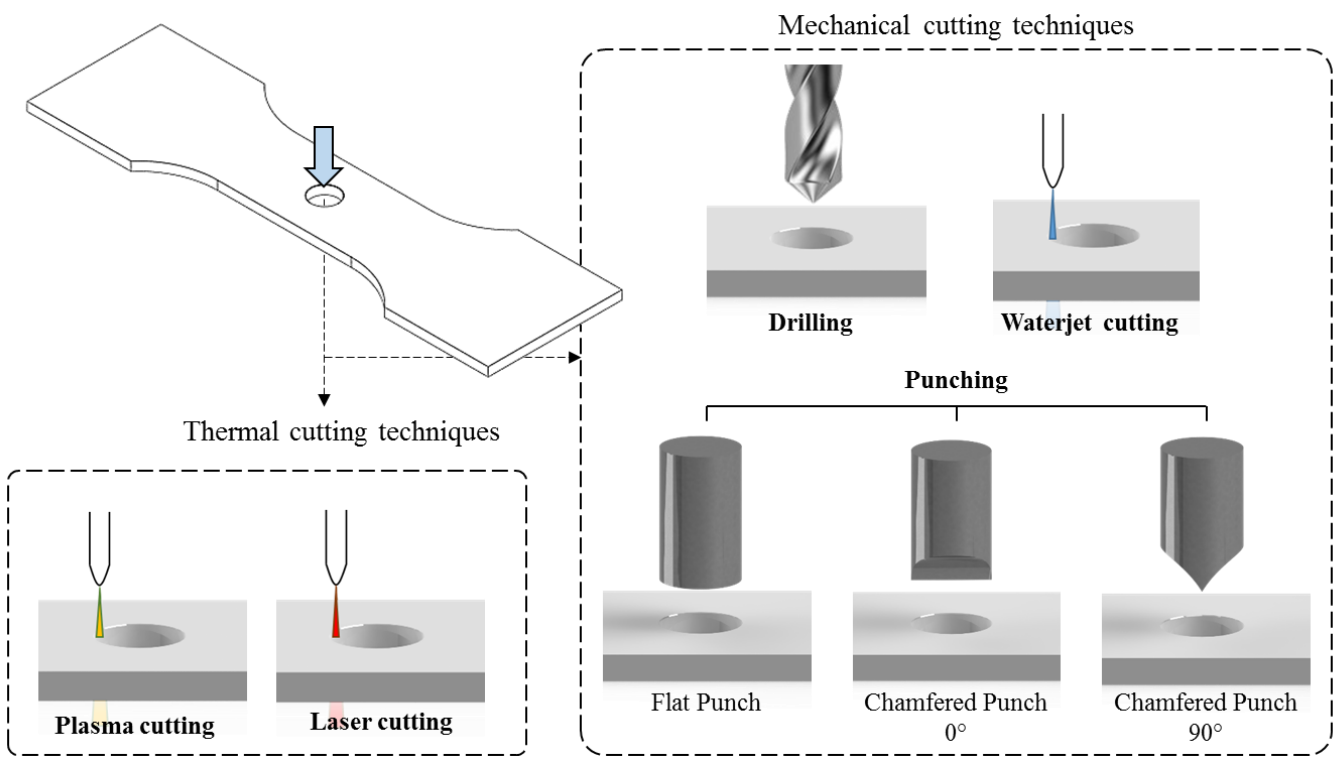

Figure 2. Mechanical and thermal cutting procedures.

\subsubsection{Punching}

During punching, a cylindrical section is removed from a workpiece by the action of a punch that pierces through the material in a punching die, leaving a hole in the workpiece. The punch shape determines the load needed to pierce through the material, but also the resulting wear on the punching tools. Flat punches require forces up to $64 \%$ higher than chamfered punches [36] but the resulting tool wear is significantly lower. In this investigation, a flat punch was compared to a chamfered punch. The orientation of the chamfered punch with respect to the axial loading was also investigated. 
The punching process parameters are summarized in Table 2. The end geometry of the flat and chamfered punch is included in Figure 3.

Table 2. Punching parameters.

\begin{tabular}{|c|c|c|c|}
\hline Parameter & \multicolumn{3}{|c|}{ Value } \\
\hline Max. punching speed & \multicolumn{3}{|c|}{$20 \mathrm{~m} / \mathrm{min}$} \\
\hline Cutting clearance & \multicolumn{3}{|c|}{$0.96 \mathrm{~mm}$} \\
\hline Punch type & Flat & Chamfered & Chamfered \\
\hline Alignment & - & $0^{\circ}$ & $90^{\circ}$ \\
\hline
\end{tabular}

(a)

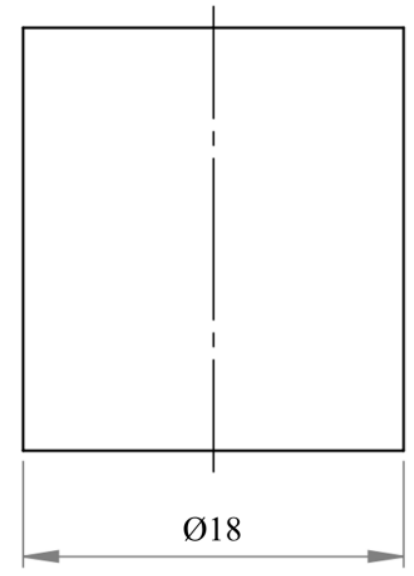

(b)

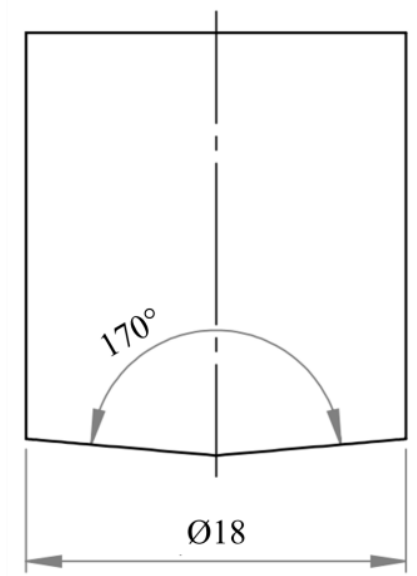

\section{Figure 3. a) Flat punch and b) chamfered punch end geometry.}

\subsubsection{Drilling}

Drilling is a cutting process during which a drill bit mounted on a machine tool, rotates at high speeds and presses against the workpiece, producing a circular hole in the material. Rotation speed and feed ratio are parameters directly affecting the hole quality [37]. In this investigation, a solid carbide drill was employed to perform the drilling. The drill was mounted in a Kunzmann WF 7/3-320 CNC machine for improved accuracy. The drilling process parameters were given by the drill manufacturer and are summarized in Table 3. The drill bit type used was a VDS201F18000 VariDrill solid carbide drill [38]. 
Table 3. Drilling parameters.

\begin{tabular}{|c|c|}
\hline Parameter & Value \\
\hline Cutting speed & $80 \mathrm{~m} / \mathrm{min}$ \\
\hline Feed & $0.3 \mathrm{~mm} / \mathrm{rev}$ \\
\hline Coolant & Flood \\
\hline Material Removal rate & $108 \mathrm{~cm}^{3} / \mathrm{min}$ \\
\hline Torque at tool & $31.92 \mathrm{Nm}$ \\
\hline Power at tool & $4.73 \mathrm{~kW}$ \\
\hline
\end{tabular}

\subsubsection{Waterjet-cutting}

During waterjet-cutting, abrasive particles are introduced into a high-velocity jet of water using pressures up to 3800 bars (380MPa). The jet is directed towards the surface of the workpiece resulting in the base material being removed by abrasion. In this investigation, an OMAX 55100 Jet Machining Center was used to manufacture the holes. Cutting parameters were adjusted in order to produce the best possible surface quality, as shown in Table 4.

Table 4. Water-jet cutting parameters.

\begin{tabular}{|c|c|}
\hline Parameter & Value \\
\hline Normal offset & $1.27 \mathrm{~mm}$ \\
\hline Radial offset & $0.32 \mathrm{~mm}$ \\
\hline High pressure setting & $379.2 \mathrm{MPa}(55000 \mathrm{psi})$ \\
\hline Low Pressure setting & $137.9 \mathrm{MPa}(20000 \mathrm{psi})$ \\
\hline Mixing tube diameter & $0.76 \mathrm{~mm}$ \\
\hline Jewel diameter & $0.30 \mathrm{~mm}$ \\
\hline Abrasive flow rate & $0.31 \mathrm{Kg} / \mathrm{min}$ \\
\hline
\end{tabular}

\subsubsection{Laser-cutting}

Laser-cutting is a process that employs a focused laser beam to selectively melt the material in the workpiece, producing in this way a high-quality cut edge. Laser-cutting was performed with a Trumpf TruLaser 3040 laser cutting machine. The cutting parameters are summarized in Table 5. 
Table 5. Laser-cutting parameters.

\begin{tabular}{|c|c|}
\hline Parameter & Value \\
\hline Beam power & $3500 \mathrm{~W}$ \\
\hline Cutting speed & $2.7 \mathrm{~m} / \mathrm{min}$ \\
\hline Nozzle diameter & $1 \mathrm{~mm}$ \\
\hline Nozzle distance & $0.7 \mathrm{~mm}$ \\
\hline Focus diameter & $0 \mathrm{~mm}$ \\
\hline Oxygen pressure & $0.6 \mathrm{bar}$ \\
\hline
\end{tabular}

\subsubsection{Plasma}

Plasma-cutting is a process that cuts through electrically conductive materials by means of an accelerated jet of hot plasma. The plasma arc is formed between the tungsten electrode and the target surface and it reaches temperatures up to $25000 \mathrm{~K}$ [39]. Due to these extreme temperatures, plasma cut edges show a large Heat Affected Zone (HAZ) [40] in which the microstructure of the base metal is modified, affecting the material behaviour. Plasma-cut samples were produced with an ESAB Combirex DX 3500 plasma cutting machine. Plasma-cutting parameters are shown in Table 6.

Table 6. Plasma-cutting parameters

\begin{tabular}{|c|c|}
\hline Parameter & Value $(\mathbf{t}=\mathbf{6} \mathbf{~ m m})$ \\
\hline Current & $100 \mathrm{~A}$ \\
\hline Nozzle & $4.1 / 1.4(\mathrm{~mm})$ \\
\hline Speed & $2159 \mathrm{~mm} / \mathrm{min}$ \\
\hline Torch standoff & $4 \mathrm{~mm}$ \\
\hline Height control & Not Active \\
\hline
\end{tabular}

\subsection{Hole geometry evaluation}

The mechanism for hole-making widely differs from one technique to another, which affects the final geometrical shape of the produced hole. The geometrical inaccuracies might compromise the usability of certain techniques in applications where high-precision holes are required. In the present research, the overall shape of the produced holes has been studied for each cutting procedure. A Mitutoyo BX303 Manual Co-ordinate Measuring Machine with a resolution of $1 \mu \mathrm{m}$ was used to measure the 
diameter of the hole along the thickness of the sample. Twelve point wise measurements were obtained at every millimetre of the hole depth. The hole diameter per hole depth was then calculated using a Gaussian fit.

\subsection{Micro hardness mapping}

Measuring and comparing the hardness distribution between different techniques allows to assess the suitability and limitations of each hole making process. In the present research, an indentation map for each procedure was produced with indentation step sizes of $500 \mu \mathrm{m}$ in different lines parallel to the surface, as in the investigation performed by Valtinat and Huhn [27]. The spacing between microindentations complies with the Vickers hardness test standard for metallic materials [41]. The hardness measurements were performed with a Struers DuraScan G5 automated hardness tester.

\subsection{Fatigue Testing}

The dog-bone specimens containing the holes were tested in a Zwick HA100 servo-hydraulic load frame with a maximal axial load of $100 \mathrm{kN}$. A stress ratio of $\mathrm{R}=0.1$ has been chosen for the tests, as it is common in both bridge structures and yellow goods, such as earth moving, construction and lifting equipment [42]. The frequency of the tests was set to $25 \mathrm{~Hz}$. Fatigue tests were performed at a single load level, with an applied nominal stress range of $225 \mathrm{MPa}$. This stress range was chosen after an initial experimental study with the intention of obtaining an average number of 1 million cycles between all holing conditions. The run-out number of cycles was set to $5 \times 10^{6}$ fatigue cycles. Three repetitions were performed for each test condition, resulting in a total test number of 21 fatigue tests. It is worth pointing that an additional fatigue test for each grade was performed for drilled samples with smoothed edges due to the findings during the experimental work, as it will be discussed in Section 3.5. 


\section{Results and discussion}

\subsection{Microstructural characterization}

The microstructure of the S500MC is shown in Figure 4 (a) at low magnification using the LOM. The fine size of the constituents required high magnification for a more accurate phase identification. In Figure 4 (b), a SEM micrograph is displayed. The microstructure consists of ferrite and fine colonies of perlite. Additionally, carbides were found with spherical morphology, precipitated at the ferrite grain boundaries and occasionally inside the grains.

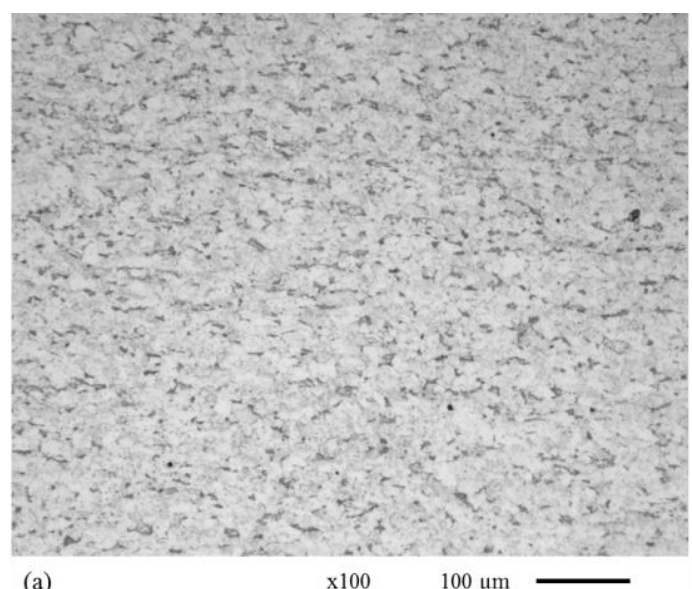

(a)

$\mathrm{x} 100 \quad 100 \mu \mathrm{m}$

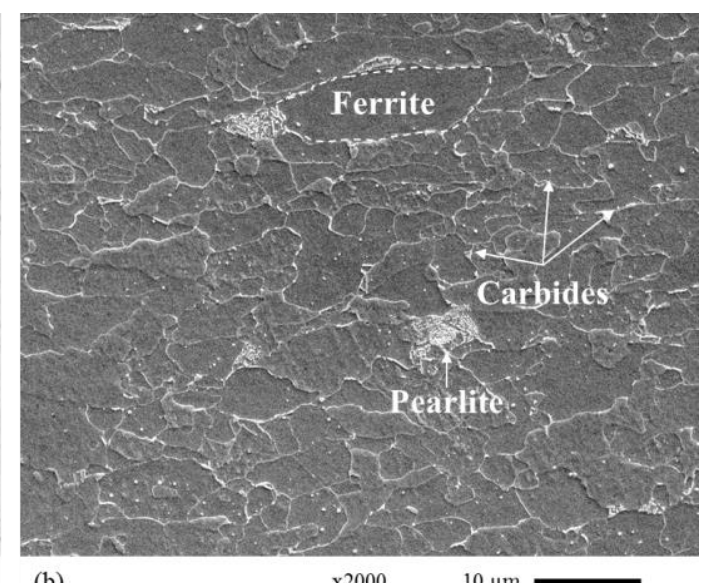

(b)

$\mathrm{x} 2000$

Figure 4. Microstructure micrograph obtained by a) LOM and b) SEM.

\subsection{Hole surface evaluation}

Notable differences were observed between holes produced by each cutting technique. In punched holes (Figure 5 (a)) there is an initial section in which the material appears to be flowing from the edge into the hole in the cutting direction. This zone is followed by the section in which shear-cutting occurs. After the shear-cutting zone, the hole starts to widen conically, and large shear dimples are observed. 

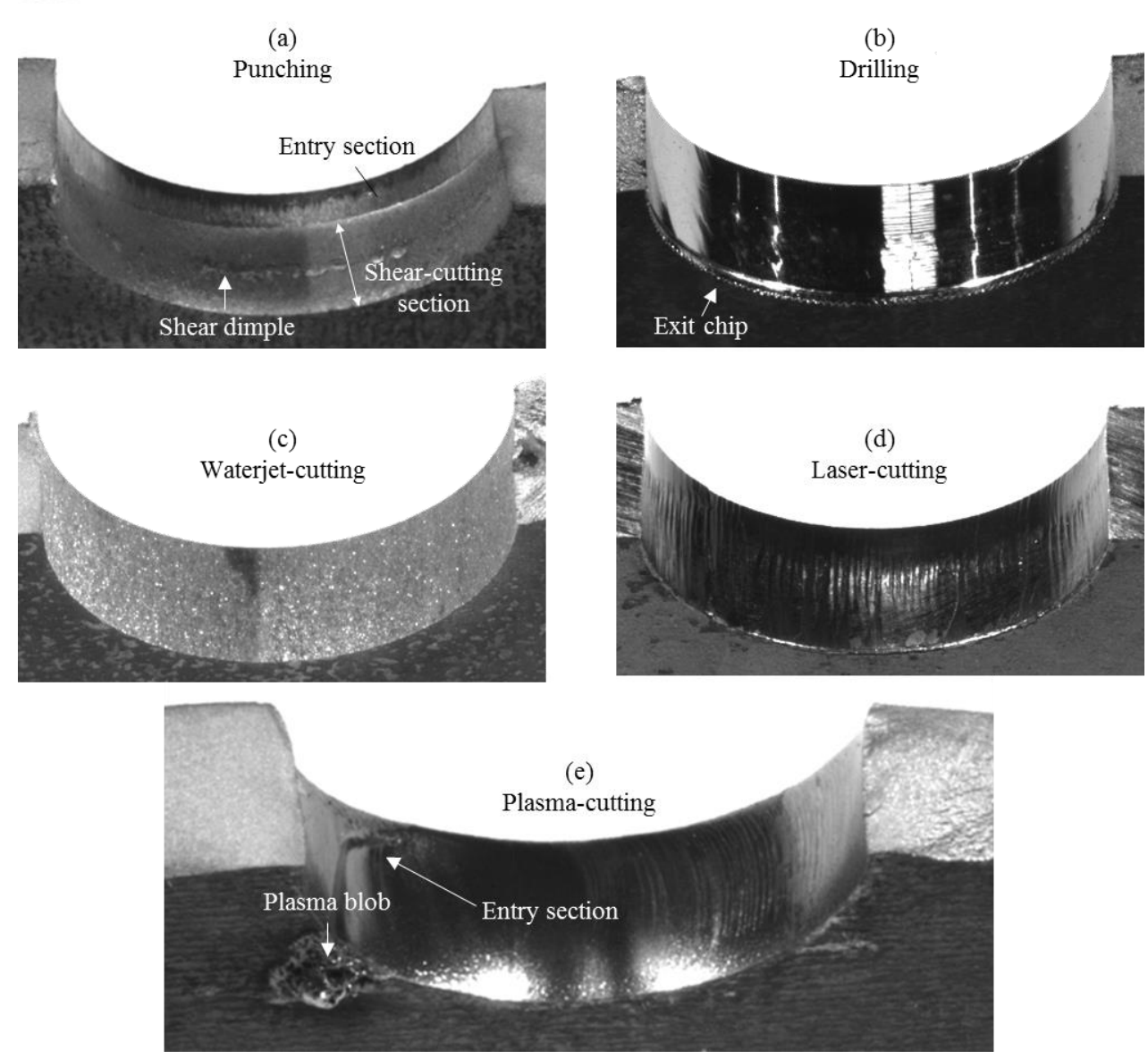

Figure 5. Hole surfaces: a) Punched, b) Drilled, c) Waterjet-cut, d) Laser-cut and e) Plasmacut

Drilled samples, on the other hand, present a constant smooth surface along the hole thickness with a chip formed at the exit side (Figure 5 (b)). This chip is usually removed with a deburring tool in real applications. In the present study, both samples with the chip left intact to avoid any type of "post-treatment" effect and the chip removed were studied.

The waterjet-cut hole, shown in Figure 5 (c), displays a rough and coarse-grained surface, which is produced by the abrasive nature of the cutting process. Normally, the waterjet deflects while cutting through the material and striations are visible across the cut edge [43]. This effect becomes more significant with higher cutting speeds. However, the cutting speed selected in this study was aimed at producing high-quality surface finish and therefore, the striations cannot be distinguished. 
The surface generated by laser cutting, displayed in Figure 5 (d), is smooth but covered by the characteristic striation pattern found in $\mathrm{CO}_{2}$ laser cutting. A similar striated surface is observed along the plasma-cut hole (Figure 5 (e)). However, the hole surface finish at the location where the plasma is firstly applied to the material significantly differs from the rest of the hole. This section is characterized by the presence of a large and curved striation at the hole surface together with a plasma blob at the point the plasma exits the material. In order to avoid any effect caused by this distinct surface condition, the plasma-cutting process was adjusted so the entry point of the plasma jet was not located at the expected fracture location. (mid-section of the hole) but at an angle of 45 degrees with respect of the axial loading.

The produced hole surfaces were further studied under the SEM. In Figure 6, SEM micrographs for punched samples are shown, together with a schematic view of the punched hole. The first entry section presents a smooth and featureless surface due to the high total strain and strain rate. On the other hand, the type of punch does have an influence on the features of the surface, as delamination and cracks were observed at the location where the sharp edges of the chamfered punch entered the material (Figure 6 (above)). The shear-cutting section Figure 6 (below) is characterised by the presence of dimples. These dimples, normal to the hole surface, are elongated in the direction of the punch travel. 


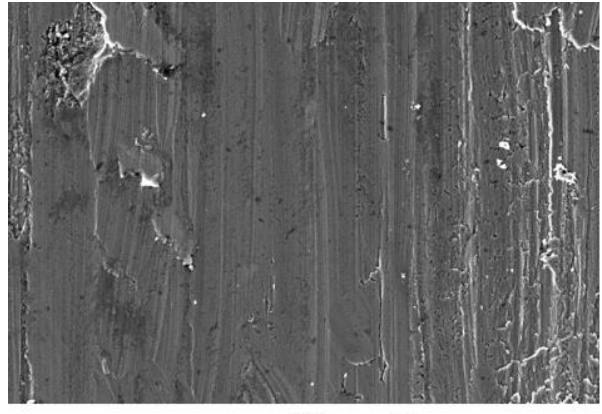

Flat Punch

$\mathrm{x} 500$

$50 \mu \mathrm{m}$

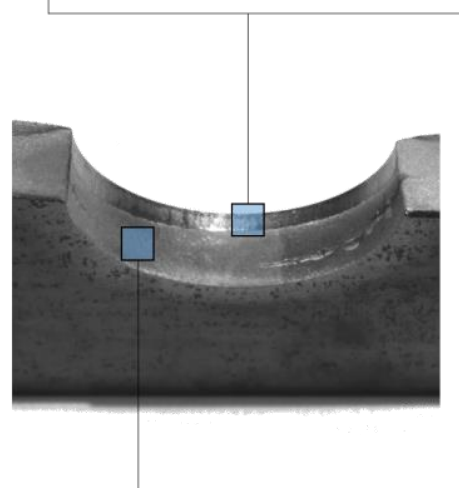

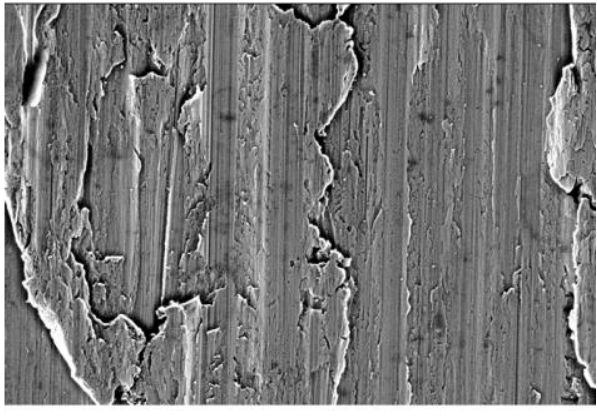

Sharp Edge

$\mathrm{x} 500$

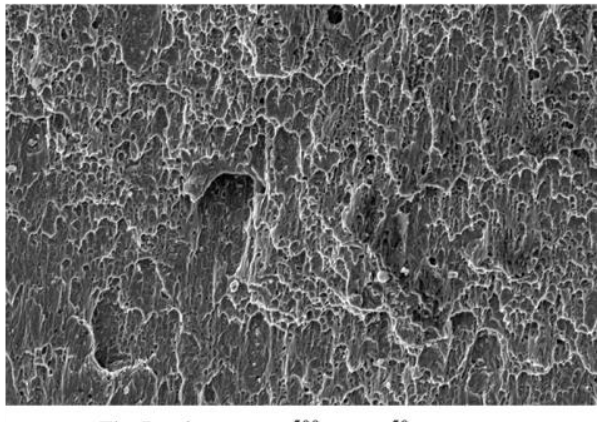

$\mathrm{x} 500$

Figure 6. Punched surface: (above) Entry section produced by flat punch and the sharp edge. (below) Shear-cutting section produced by flat punch.

The drilled hole surfaces present a constant and smooth surface, shown in Figure 7 (a). No distinct features could be observed in the cut surface due to precise drilling process. The waterjet-cut surface presented highly abraded traces of material together with hollow sections where the material was removed by the abrasive jet, as shown in Figure 7 (b). The surface produced by laser-cutting is covered by a regularly distributed crack pattern. These cracks are likely to grow during the solidification process after the material was melted to create the hole. The crack pattern can be observed in Figure 7 (c). Additionally, protruding acicular structures were observed in the laser-cut surface. These structures are caused by surface stress relief, indicating martensite formation at the regions close to the hole. 


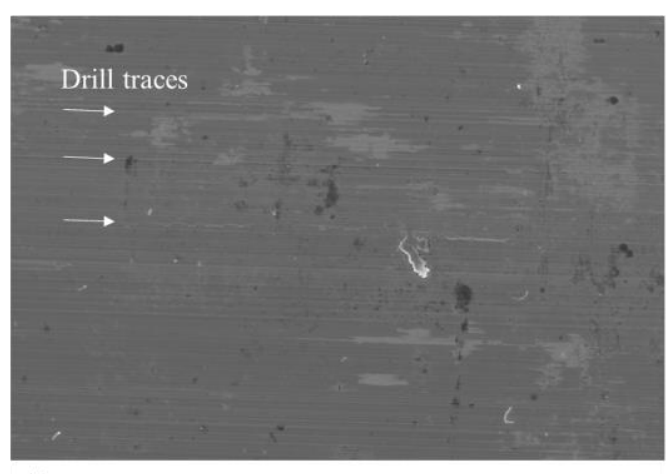

(a)

$\times 500$

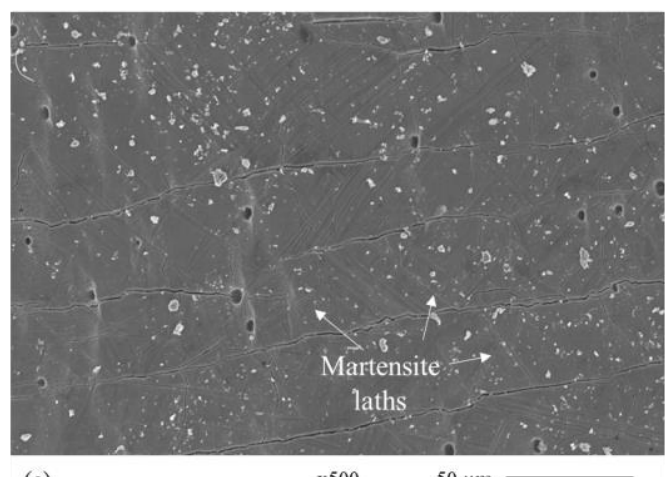

(c)

$50 \mu \mathrm{m}$

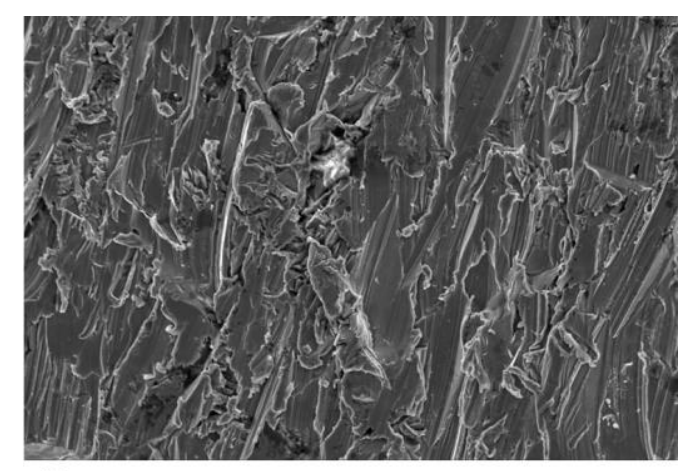

(b)

x500

$50 \mu \mathrm{m}$

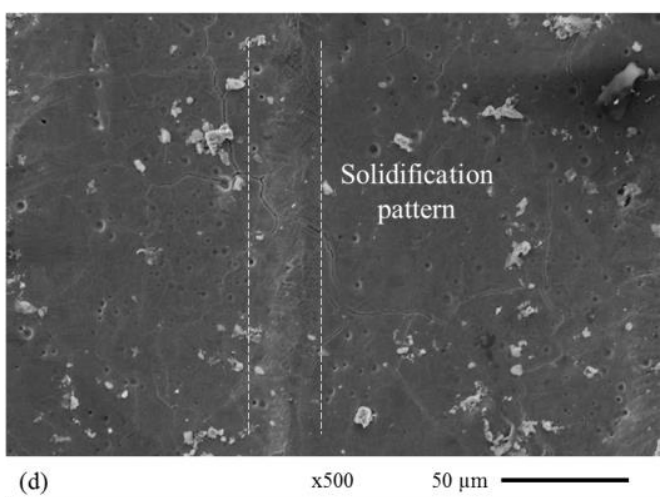

(d)

Figure 7. Hole surfaces produced by a) drilling, b) waterjet-cutting and (c) laser-cutting and (d) plasma-cutting

Finally, the surface produced by plasma-cutting is displayed in Figure 7 (d). The resulting surface is smooth but covered by a crack pattern similar to the surface observed in laser-cutting. The plasmacut surface is characterised by the presence of solidification patterns elongated in the direction of the hole where the material was removed. This shows that the material at this location was extensively melted and re-solidified. Acicular formations are also noticed but not as clear and as regular as in in the laser cut samples. This can be attributed to the different cooling rates achieved by the two techniques. The features of the plasma entry region, namely the plasma entry line and the plasma blob, were also further studied by SEM. The region in which the plasma first comes in contact with the material, shown in Figure 8 (a), is formed by a large striation which severely distorts the hole geometry. The striation is directed along the hole direction and it deviates towards the hole entry edge. Although there is a sudden change in the geometry of the hole along the striation, no cracks were observed in any of the specimens at this location. The plasma blob, shown in Figure 8 (b), is 
enclosed inside the lower hole edge and it is covered by large pores, which may act as potential crack initiation sites.

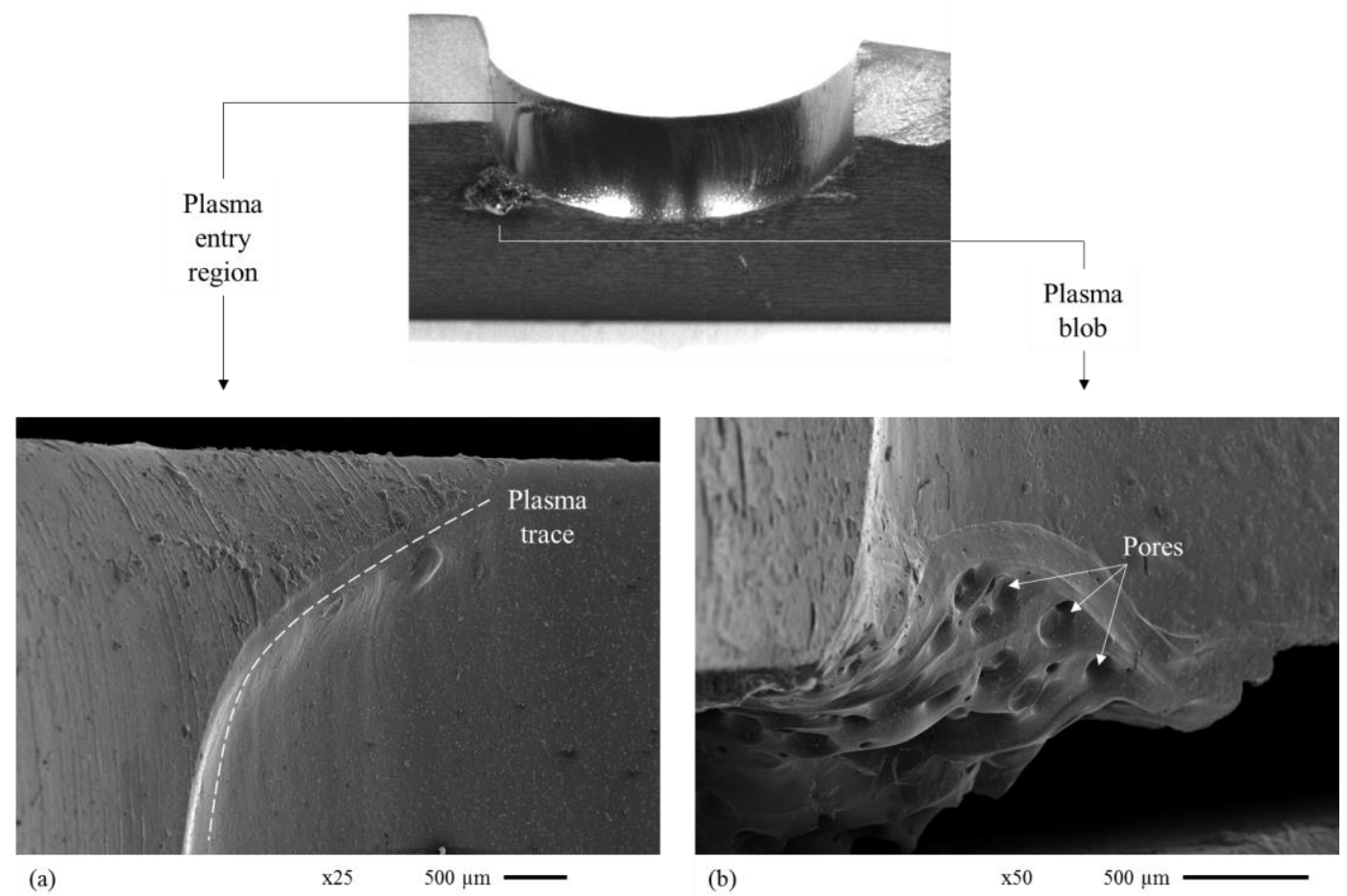

Figure 8. Plasma hole defects: a) entry region and b) plasma blob.

Due to the evidence showing microstructural changes in the holes produced by plasma and laser-cut, the cross-section of the material adjoining the hole was also studied under the SEM. In Figure 9, the cross-sections of the laser (above) and plasma (below) cut holes are displayed. The presence of a HAZ can immediately be noticed in all displayed samples. The analysis of the microstructure reveals that the HAZ is formed by a martensitic microstructure in all cases, confirming the observations regarding the presence of acicular formations in both the plasma and the laser hole surfaces. The extension of the laser HAZ is around $95 \mu \mathrm{m}$, while the plasma HAZ layer is significantly larger, about $250 \mu \mathrm{m}$. This is due to the difference between the laser and the plasma heat source geometries. The plasma cut technique uses plasma in argon atmosphere, which results in a gaussian temperature distribution at the surface of the workpiece, similar to the ones obtained during arc welding. On the other hand, in laser cutting a focused laser beam is used, resulting in a much more limited HAZ [44]. 


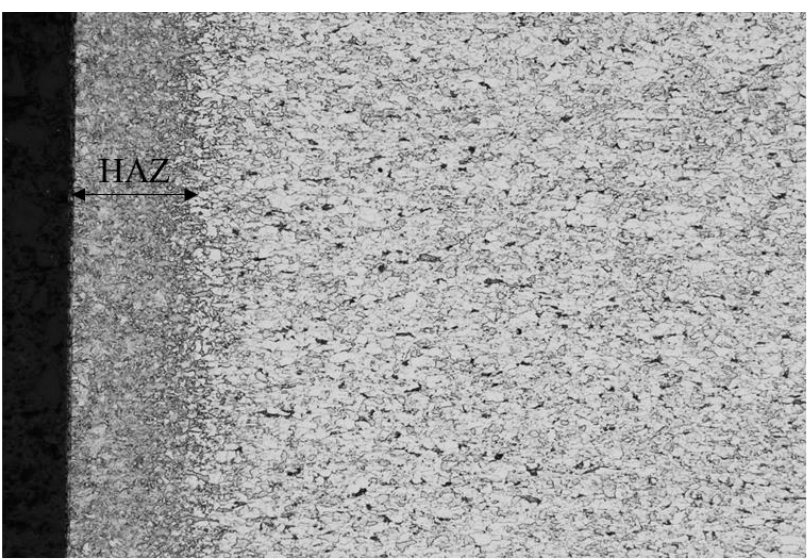

(a) Laser $\mathrm{x} 500$
$50 \mu \mathrm{m}$

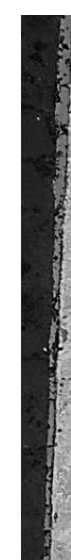

(b) Plasma
HAZ

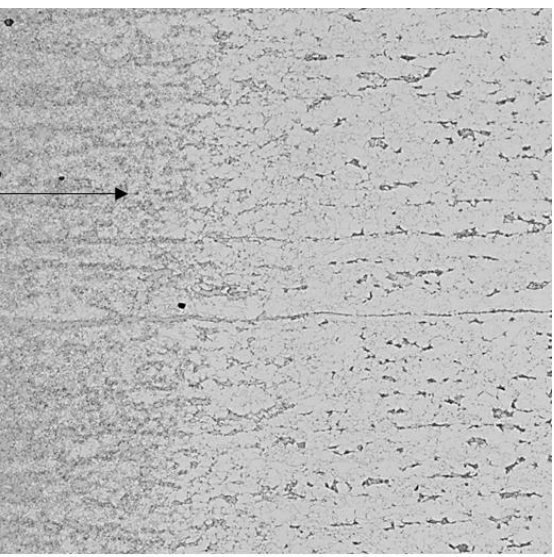

$\mathrm{x} 500$

$50 \mu \mathrm{m}$

Figure 9. Cross section of thermal-cut holes: a) Laser and b) Plasma.

\subsection{Hole geometry evaluation}

In Figure 10, the averaged hole diameter at different depths is represented for each hole-making procedure. The variation of the obtained results between repetitions is low and the maximum value of the standard deviation (which has not been included in the graph to improve its clarity) equals $0.047 \mathrm{~mm}$ and corresponds to the chamfered punch at $90^{\circ}$.

Notable discrepancies exist between the different cutting techniques. Drilling results in the most accurate and constant hole radius. Waterjet-cutting, on the other hand, produces a larger hole edge at the entry side of the hole which gradually decreases towards the exit side of the hole, creating an undersized hole diameter. Punching yields an accurate hole diameter at the entry side but, after the mid-section of the hole, a large oversized $(\approx+0.7 \mathrm{~mm})$ hole develops towards the exit. The transition between the initial and the shear-cutting section can be clearly distinguished in Figure 10, at the location where a sudden change in the hole geometry takes place. It can also be observed that there are no clear dissimilarities between holes produced by different punching conditions. The hole produced by laser-cutting has a sinuous nature, with hole diameter oscillations along the hole depth. However, the deviation from the desired hole geometry are not as large as in punching or water-jet cutting. And finally, the hole produced by plasma-cutting shows in the largest deviations from the 
theoretical hole geometry, with the largest oversize at the entry side and the largest undersize at the hole exit.

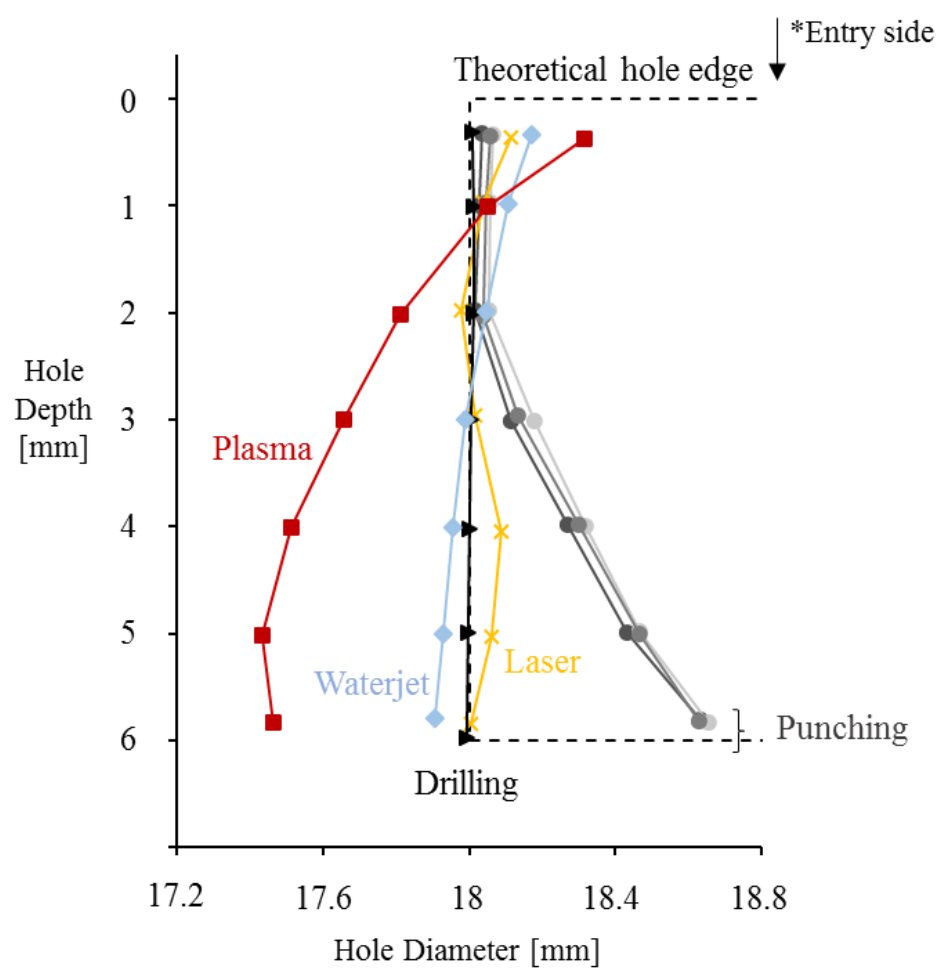

Figure 10. Hole diameter along sample thickness for waterjet-cutting, laser-cutting, drilling and punching in S500MC.

The different produced diameters by each cutting technique may limit the applicability of the technique if the final product requires low tolerance finish. The most accurate techniques in terms of hole diameters are drilling, laser-cutting and waterjet-cutting, in decreasing order of quality.

\subsection{Micro-hardness evaluation}

The results of the hardness tests reveal an increase in the hardness values near the hole edge for some of the cutting techniques. In Figure 11, the hardness distribution near the hole for various hole-making procedures is shown. It can be observed that the hardness distribution in the drilled and waterjet-cut samples is reasonably constant, with slight variations along the depth. The damage produced by these cutting processes is restricted to the removed material and its close neighbouring area is due to the abrasive-cut nature and the absence of significant thermal heating. Hardness measurements are 
limited to a distance of $100 \mu \mathrm{m}$ from the hole edge by the ISO 6507-1: 2018 [41], which might be insufficient to study the localised hardening at the hole edge.
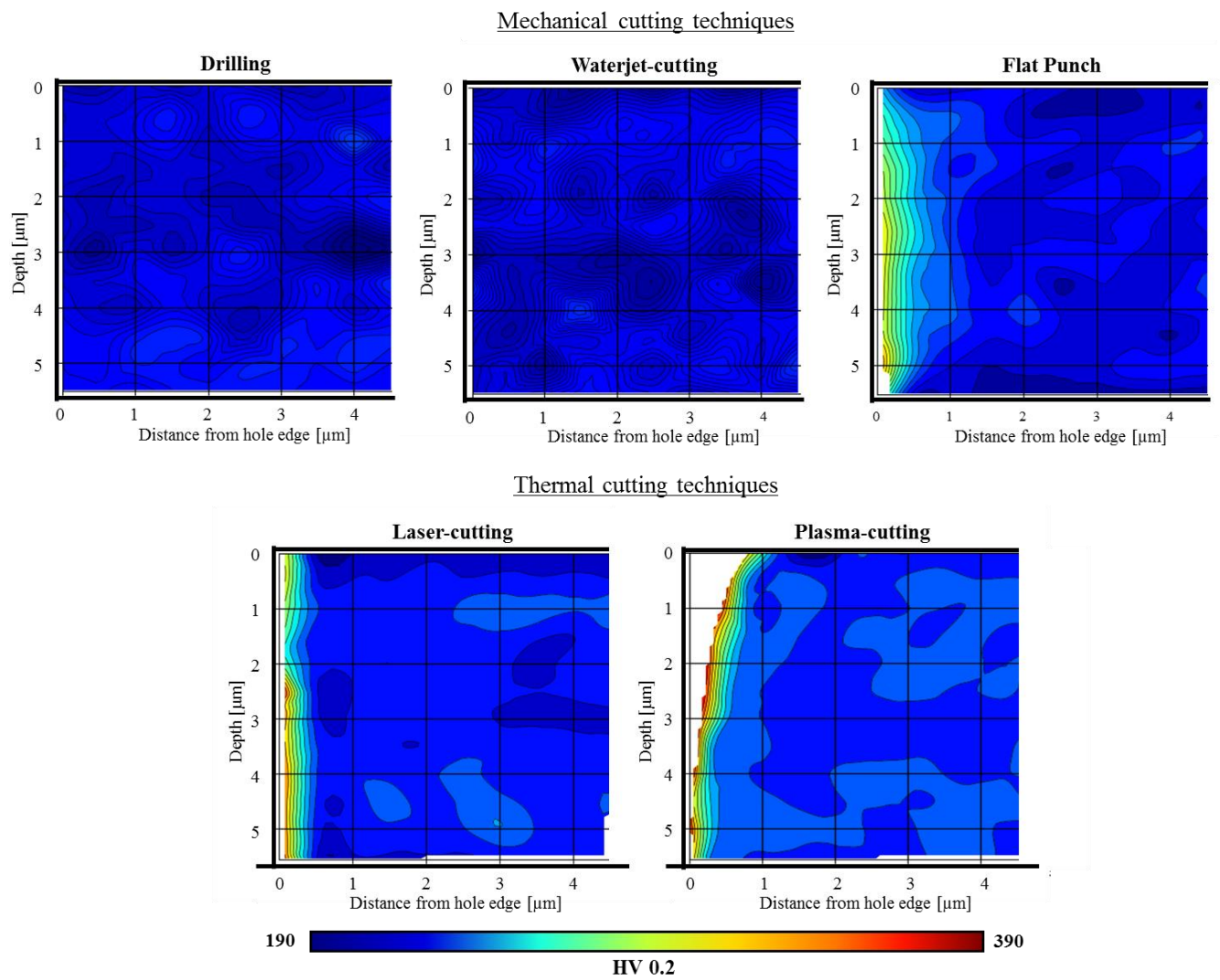

Figure 11. Hardness distribution near the hole edge in HSS grade S500MC for various holemaking procedures.

In the case of the punched samples, there is a clear hardness increase towards the hole edge. This phenomenon has already been described in punched specimens by Valtinat and Huhn [27] and can be attributed to the effect of cold-working. It should be noted that for the assessment of the work hardening state, hardness values can be misleading, since they are also increased by the presence of compressive residual stresses [45]. The increase of hardness in punched samples (flat punch) with respect to the base material hardness was found to be $62 \%$. The punch shape and orientation does not seem to play a role in the final hardening distribution near the hole. As displayed in Figure 12, the chamfered punch and the flat punch result in similar hardening distributions. 

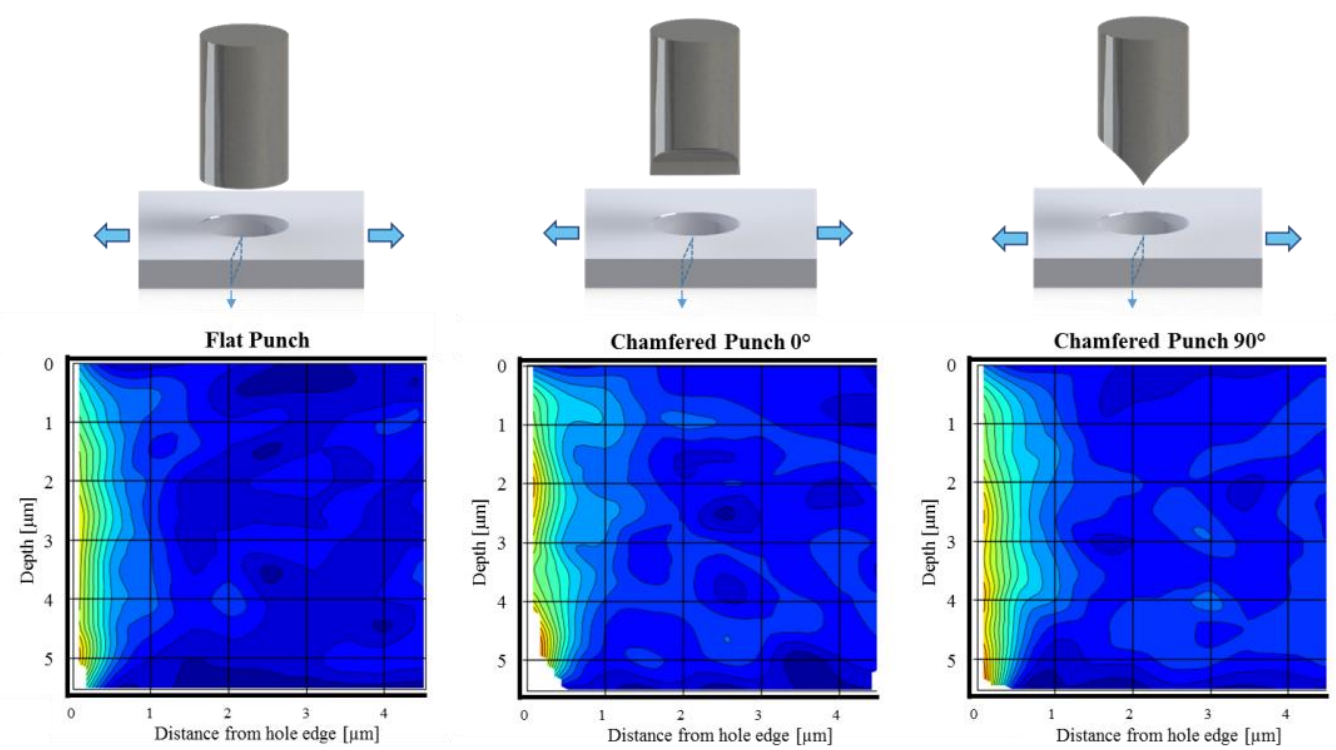

190

HV 0.2

Figure 12. Hardness distribution produced in the S500MC by a) flat punch, b) chamfered punch at $0^{\circ}$ and c) chamfered punch at $90^{\circ}$.

Laser-cut specimens also exhibit hardening near the hole edge but along a reduced extent compared to punched specimens. As previously seen in Section 3.2, the large heat input produced by the laser process, following rapid cooling, induced the formation of a thin layer with martensitic microstructure near the hole edge. This formation becomes possible due to the carbon enrichment of the surface layer, which could be a result of carbon pickup from the surrounding atmosphere during cutting. Carbon could also be found in lubricants present at the surface of the steel plates before the cutting procedure was carried out. The hardness of this layer is significantly higher than the ferritic microstructure of the S500MC.

A similar and wider HAZ was found near the hole edge in the plasma-cut samples, as presented in Section 3.2. The martensitic microstructure of this layer is also harder than the ferritic microstructure of the S500MC which results in a clear hardening towards the hole edge. A more detailed hardness analysis was performed near the hole edge, with less distance between indentations, as shown in Figure 13. 


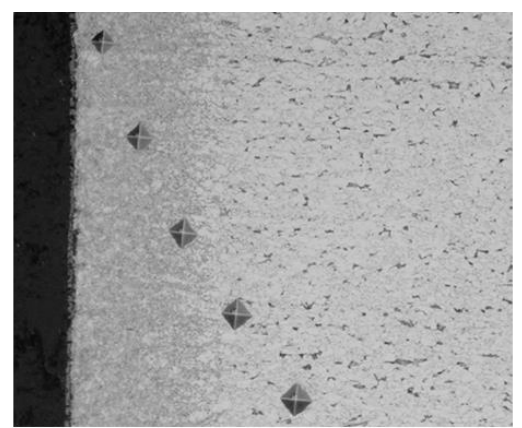

(a) Laser

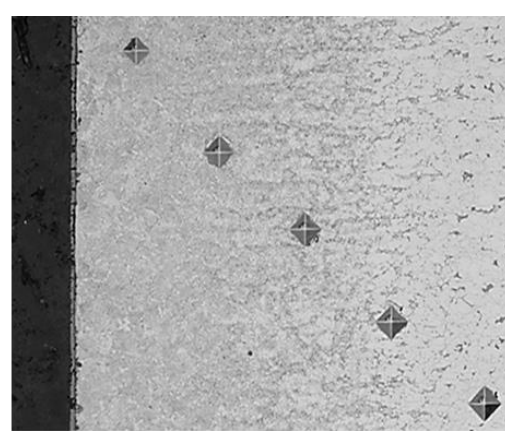

(b) Plasma

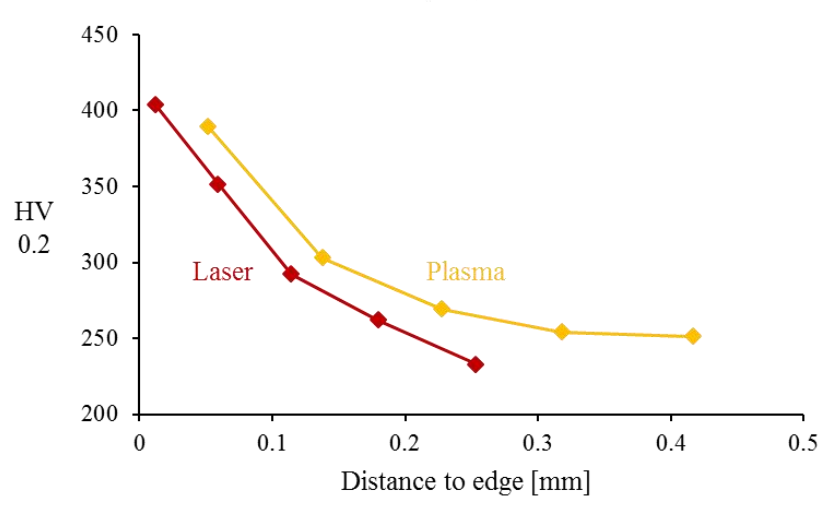

Figure 13. Hardness analysis near a) laser and b) plasma layers.

\subsection{Fatigue results}

The results of all 21 fatigue tests performed on each holed specimen are presented in this section. The tested specimens provided a fairly clear indication of the performance of each hole-making process under plain fatigue. The fatigue results for the holed specimens, tested at a nominal stress range of $225 \mathrm{MPa}$, are presented in Figure 14. Compared with the rest of the hole-making procedures, punched specimens resulted, on average, in the lowest fatigue lives. There is a slight improvement in fatigue performance when the chamfered punch is employed and its sharp edge is not facing the mid-section of the hole, which is the most common failure location. This relates to the lower presence of cracks and delamination in the punch entry section observed in Figure 6 for this particular hole-making condition. The lower surface damage produced by the chamfered punch at this specific orientation explains the slight increase in fatigue performance.

The plasma-cut samples exhibit a better fatigue performance compared to the punched specimens. A notable difference that could be observed in these samples was the fracture location. While in the rest 
of the hole-making procedures, fatigue failure always took place at the mid-section of the hole, in plasma-cut samples, fracture sometimes happened at the plasma blob caused by the plasma jet entry. However, the fatigue life results did not seem to be affected by this since the standard deviation of the fatigue results is the lowest of all the hole-making techniques. The fatigue performance of drilled samples was considerably higher than the punched ones. During these tests, it was demonstrated that the remaining exit drill chip, displayed in Figure 5 (c), had a negative effect on the fatigue behaviour. Additional tests were performed, with the drill chip removed with a manual deburring tool, which resulted in run-out fatigue tests ( $>5$ million cycles).

Waterjet-cut samples sustained 5 million fatigue cycles at this nominal stress level. Although the surface finish produced by the waterjet-cutting process can be considered comparable or rougher to the one produced by the punching process, the surface defects are more homogeneous in terms of size and distribution. Additionally, the hardness maps shown in Section 3.4 indicate that the damage produced by the waterjet process is much more limited. The fatigue performance of waterjet-cut holes is also higher than the drilled holes, most likely thanks of the absence of the large notch induced by the drill chip. The laser-cut specimens also resulted in run-out tests (5 million cycles) therefore exhibiting, together with the water-jet cut samples, the most favourable fatigue performance.

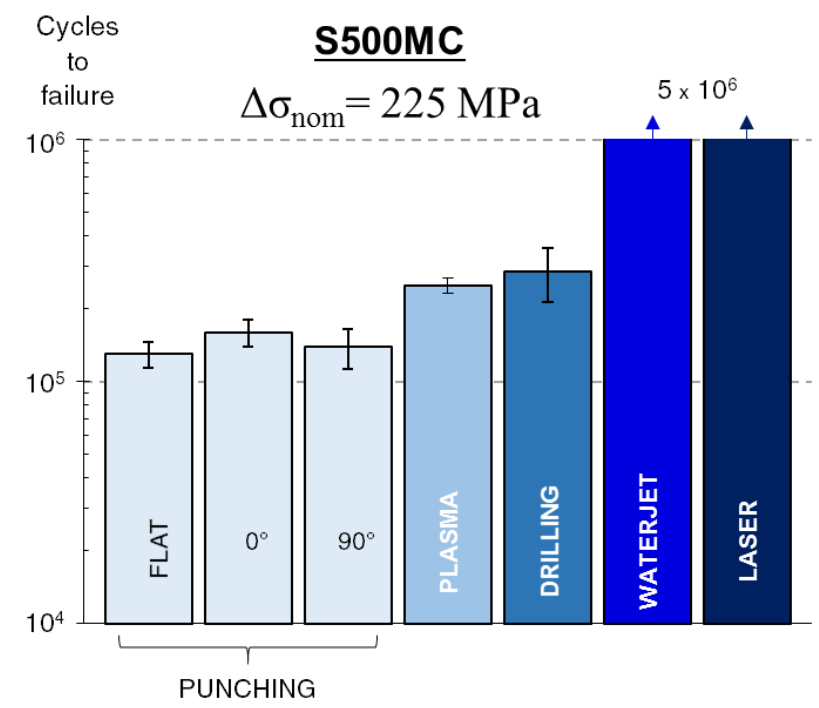

Figure 14. Fatigue results for $\operatorname{S500MC}\left(\Delta \sigma_{n o m}=225 \mathrm{MPa}\right)$. 


\subsection{Fracture analysis}

Figure 15 typically displays the fracture surface that was observed in all fractured specimens. Fatigue failure typically occurred at the middle of the sample, starting from the hole edge. Fatigue cracks propagated perpendicular to the axial load direction. After a certain distance, when the cross-section was significantly reduced, ductile failure occurred at the remaining connected material. This final fracture region is observed at $45^{\circ}$ to the plane of tensile load (angle at which the shear load is maximal) producing the characteristic cup and cone fracture shape.

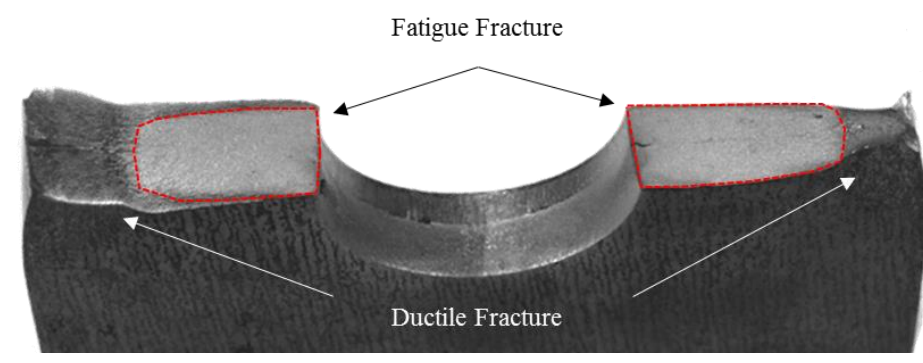

Figure 15. Fractured holed specimen.

Both the entry section and the shear cutting section of the punched holes were evaluated by SEM. Although all fractured punched specimens present cracks along the shear cutting section, failure was more likely to initiate at the lower end of the shear cutting region (Figure 16). 


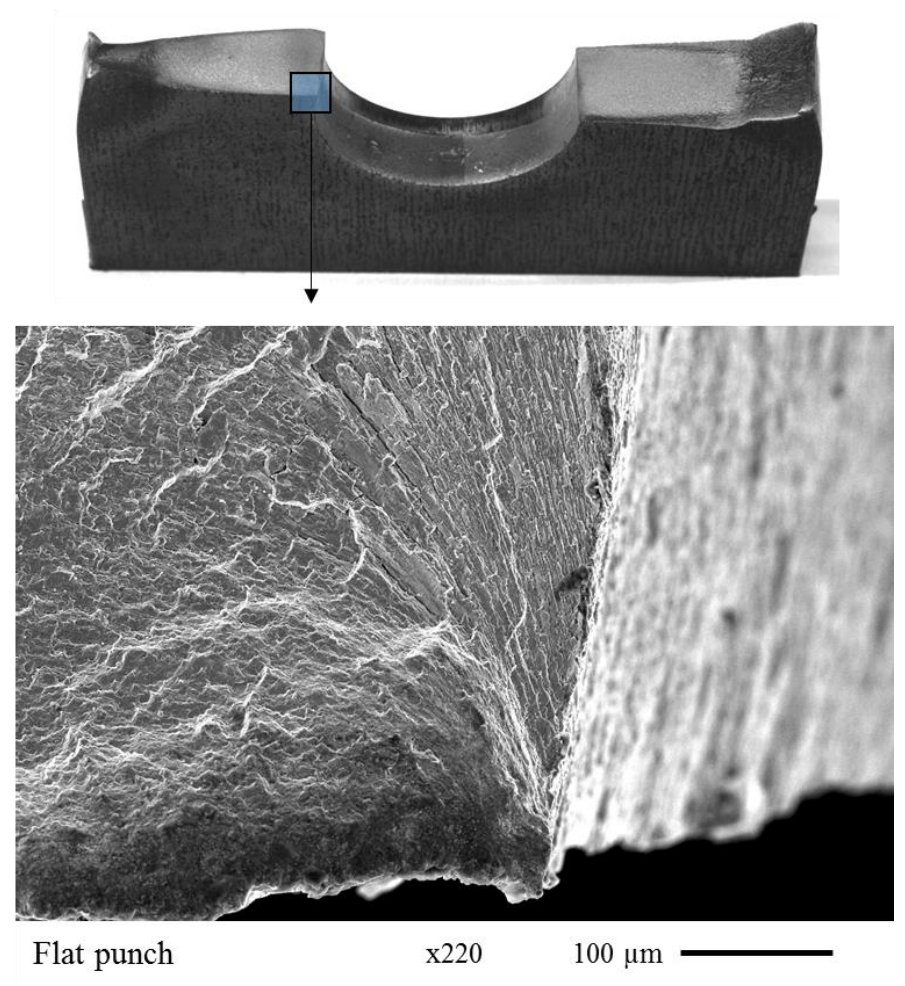

Figure 16. Fracture surfaces of punched specimens.

As previously mentioned in Section 3.5, additional tests were performed by removing the drill chip which resulted in run-out fatigue tests. Therefore, the region near the drill chip was carefully observed during SEM evaluation. The microscopic analysis of the fractured drilled samples demonstrated that the drill chip formed at the exit of the drill bit plays a critical role in the crack formation and propagation. Figure 17 (a) displays the cross section of a fractured drilled specimen. The drill chip is clearly visible, extending after the end of the hole. The interface between the drill chip and the remaining material is covered by small cracks. The presence of a large crack propagating towards the material in the hole axis direction can also be noted in Figure 17 (a). The crack originates from the damaged chip-hole interface and acts as a notch, therefore reducing the fatigue life of the specimen. The drill entry region was examined by SEM as well. As it can be observed in Figure 17 (b), the produced hole edge has a rough appearance, with multiple sharp edges. Additionally, in some specimens, cracks originating from this location were also observed. Figure 17 (b) displays a crack propagating from the entry burr towards the hole direction. Thus, it can be concluded that both edges 
should be deburred to fully take advantage of the superior surface quality and absence of residual stress produced by drilling.

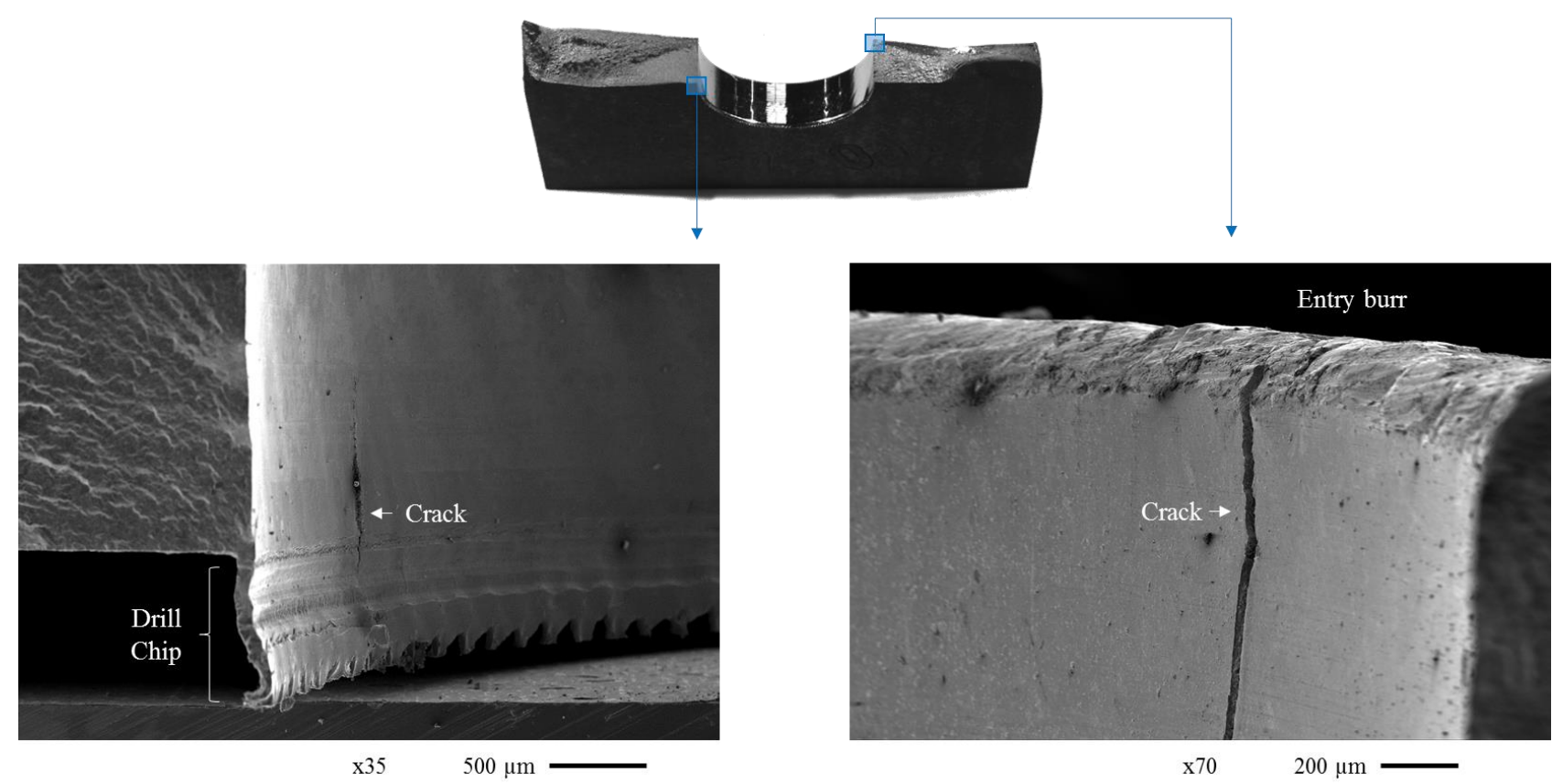

Figure 17. Fracture details of drilled hole at: a) exit drill chip and b) entry drill chip.

The waterjet-cut and laser-cut samples did not fail within the specified loading cycles, so no evaluation of the fracture surface was possible in the present investigation.

Due to the considerable amount of samples fracturing at the plasma blob location instead of at the middle of the hole, this area was carefully examined by SEM. It was observed that the pores contained in the plasma blob interfered with the hole geometry and were potentially acting as a notch for crack initiation (Figure 18 (a)). However, multiple crack initiation points were also found in the opposite side of the plasma-jet entry. It can be noted in Figure 18 (b) that cracks clearly initiate and propagate from the surface defects found along the hole geometry. This was observed in all specimens, regardless of fracture occurring at the plasma blob or not. Additionally, it was seen in Section 3.5 that the fatigue performance of plasma-cut specimens was constant, independently of the location of the fracture, which may indicate that the predominant crack initiation takes place in the hole surface regardless of the presence of the blob. 


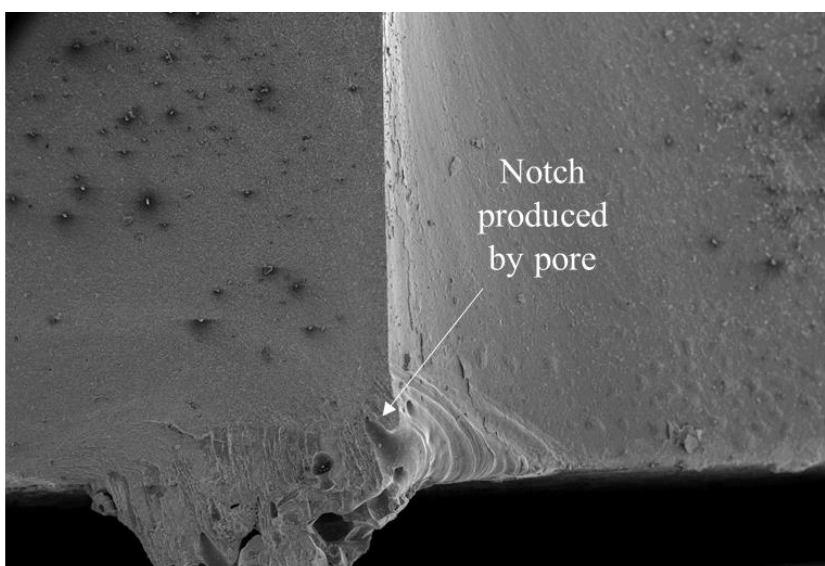

(a)

x 25

$500 \mu \mathrm{m}$

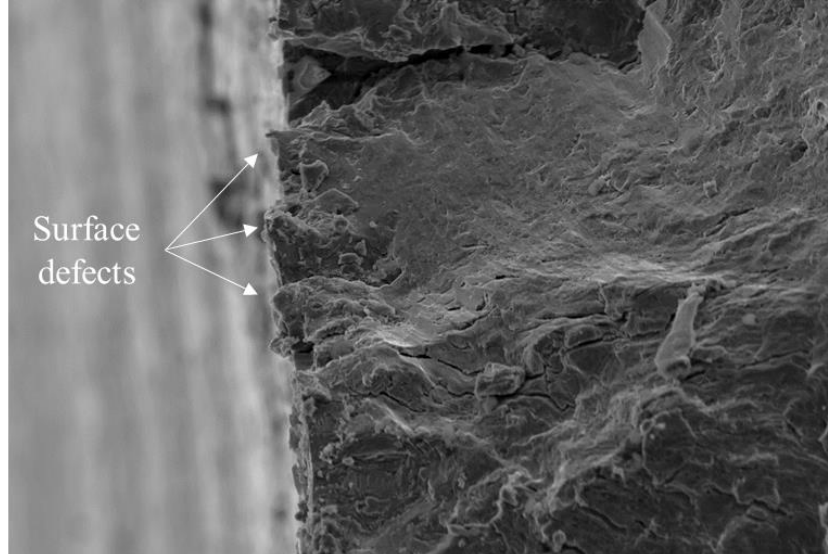

(b)

Figure 18. Fracture surfaces at a) plasma blob and b) mid-hole surface (S500MC).

\section{Conclusions}

In this study, the effect of several hole-making processes on the fatigue performance of HSS plates was investigated. The commercial grade S500MC was studied. The following conclusions could be formulated for each hole-making processes:

- Punching: The punched samples exhibited the lowest fatigue performance of all considered hole-making processes. The typical hole surface produced by punching is dominated by macro-defects such as shear dimples. The resulting hole has a conical shape with an oversized diameter at the punch exit hole side. The hardness maps indicated large cold-hardening towards the hole edge. The shape and orientation of the punch affected the fatigue performance of the specimen, and the chamfered punch slightly improves fatigue performance whenever the sharp edge was not facing the expected failure location.

- Plasma-cutting: The plasma-cut samples performed better in fatigue compared to the punched specimen. The hole surface was characterised by the presence of a large striation and a plasma blob at the location where the plasma jet entered the material. The hole shape produced by plasma was the most distorted compared to the rest of the techniques. The fracture surface analysis showed that the surface defects induced by the plasma jet at the entry 
point can act as a notch for fatigue crack initiation and, therefore, should be located far away from the expected fracture location.

- Drilling: The fatigue performance of the drilled samples was comparable to the plasma-cut specimens. Drilling produced holes with a seamless and uniform surface, the best geometrical accuracy and little or no material hardening near the hole edge. During fracture evaluation, it was found that the drill chip acted as a notch for cracks to initiate and that its removal on both edges (with a simple manual deburring tool) resulted in considerably improved fatigue performance.

- Waterjet-cutting: Waterjet-cut samples performed better than plasma-cut and drilled samples under fatigue loading. The hole surface was covered by micro-defects and traces of removed material, from which cracks initiate during fatigue loading. Due to the abrasive nature of the process, no hardening was induced into the material.

- Laser-cutting: Laser-cutting proved to be the hole-making procedure with the best fatigue performance. The micro-hardness maps and the hole surface evaluation revealed the presence of a layer with martensitic microstructure, formed during the thermal-cutting process. The improved fatigue performance is believed to be produced by a combination of the smooth hole surface, the martensitic layer and the induced residual compressive stresses around the hole.

The results of this study indicate how different hole making processes affect the hole geometry, its surface finish and the surrounding material and how they influence the fatigue performance of a plated sample containing the hole. Aspects like the hole morphology and geometrical distortions were found not to affect the fatigue performance as much as the presence of large individual defects. The elimination of these defects, such as the drill chip or the plasma blob, would therefore improve the fatigue behaviour of the holes. The findings of this research may be applied to evaluate the fatigue behaviour of bearing-type bolted connections, where the bolt bears against the hole to transfer the connection load. The most appropriate hole-making technique could be then be chosen depending on 
the desired loading condition, geometrical requirements or economic aspects. Future research will focus on applying the studied hole-making procedures to real bolted connections, preloaded and nonpreloaded, to evaluate the fatigue behaviour of the holes in a bolted configuration.

This study also does not compare the behaviour of different grades of steel and focuses on the S500MC, increasingly being used in structural applications suffering fatigue problems. Other grades, with increased resistance and decreased ductility, might behave differently. Future work will extent the study to a wider range of HSS that are generally used within the same range of applications, with yield strengths ranging from $500 \mathrm{MPa}$ to $1000 \mathrm{MPa}$. The combined fatigue results of different HSS grades may also serve as validation for the implementation of fatigue prediction criteria in Finite Element Model analyses.

\section{Acknowledgments}

This work was supported by the European Research Project DURAMECH: "Towards Best Practice for Bolted Connections in High Strength Steels" [project number 709962 (2016)].

\section{References}

[1] Jensen L, Bloomstine ML. Application of high strength steel in super long span modern suspension bridge design. NSCC. 2009:494-501.

[2] Miki C, Homma K, Tominaga T. High strength and high performance steels and their use in bridge structures. Journal of Constructional Steel Research. 2002;58:3-20.

[3] Bjorhovde R. Development and use of high performance steel. Journal of Constructional Steel Research. 2004;60:393-400.

[4] Billingham J, Sharp J, Spurrier J, Kilgallon P. Review of the performance of high strength steels used offshore. Health Saf Exec. 2003;111.

[5] Petersen RI, Agerskov H, Martinez LL. Fatigue Life of High-strength Steel Offshore Tubular Joints. 1996.

[6] Veljkovic M, Husson W. High-Strength Steel Tower for Wind Turbine. Final Report RFSR-CT2006-00031. Brüssel (B): RFCS Publications, European ...; 2010.

[7] Takahashi M. Development of high strength steels for automobiles. Shinnittetsu Giho. 2003:2-6.

[8] Zhang Y, Lai X, Zhu P, Wang W. Lightweight design of automobile component using high strength steel based on dent resistance. Materials \& Design. 2006;27:64-8.

[9] Sperle J-O. High strength sheet and plate steels for optimum structural performance. SSAB Tunnplåt $\mathrm{AB}$, Borlänge. 1997.

[10] Senuma T. Physical Metallurgy of Modern High Strength Steel Sheets. ISIJ International. 2001;41:520-32. 
[11] Willms R. High strength steel for steel constructions. Nordic Steel. 2009.

[12] Anami K, Miki C. Fatigue strength of welded joints made of high-strength steels. Progress in Structural Engineering and Materials. 2001;3:86-94.

[13] Lee CK, Chiew SP, Jiang J. Residual stress of high strength steel box T-joints: Part 1: Experimental study. Journal of Constructional Steel Research. 2014;93:20-31.

[14] Jiang J, Zhang J, Liu J, Chiew SP, Lee CK. Effect of welding and heat treatment on strength of high-strength steel columns. Journal of Constructional Steel Research. 2018;151:238-52.

[15] Zhao MS, Chiew SP, Lee CK. Post weld heat treatment for high strength steel welded connections. Journal of Constructional Steel Research. 2016;122:167-77.

[16] Chen C, Chiew S-P, Zhao M-S, Lee C-K, Fung T-C. Welding effect on tensile strength of grade S690Q steel butt joint. Journal of Constructional Steel Research. 2019;153:153-68.

[17] Yildırım HC. Recent results on fatigue strength improvement of high-strength steel welded joints. International Journal of Fatigue. 2017;101:408-20.

[18] RFCS project FATWELDHSS, Improving the fatigue life of high strength steel welded structures by post weld treatments and specific filler material (2010).

[19] Puthli R, Fleischer O. Investigations on bolted connections for high strength steel members. Journal of Constructional Steel Research. 2001;57:313-26.

[20] Može P, Beg D. High strength steel tension splices with one or two bolts. Journal of Constructional Steel Research. 2010;66:1000-10.

[21] Može P, Beg D. Investigation of high strength steel connections with several bolts in double shear. Journal of Constructional Steel Research. 2011;67:333-47.

[22] Guo H, Xiao F, Liu Y, Liang G. Experimental and numerical study on the mechanical behavior of Q460D high-strength steel bolted connections. Journal of Constructional Steel Research. 2018;151:108-21.

[23] Hämäläinen O-P, Björk T. Fretting fatigue phenomenon in bolted high-strength steel plate connections. Steel Construction. 2015;8:174-8.

[24] Jiménez-Peña C, Talemi RH, Rossi B, Debruyne D. Investigations on the fretting fatigue failure mechanism of bolted joints in high strength steel subjected to different levels of pre-tension. Tribology International. 2017;108:128-40.

[25] Brown JD, Lubitz DJ, Cekov YC, Frank KH, Keating PB. Evaluation of influence of hole making upon the performance of structural steel plates and connections. 2007.

[26] Garcia T, Cicero S, Carrascal I, Madrazo V, Álvarez JA. Effect of cutting method on fatigue crack initiation and fatigue life of structural steel S355M. ASME 2014 Pressure Vessels and Piping Conference: American Society of Mechanical Engineers; 2014. p. V003T03A54-VT03A54.

[27] Valtinat G, Huhn H. Bolted connections with hot dip galvanized steel members with punched holes. Proceedings of Connections in Steel Structures V. 2004:297-310.

[28] Bursi OS, D'Incau M, Zanon G, Raso S, Scardi P. Laser and mechanical cutting effects on the cut-edge properties of steel S355N. Journal of Constructional Steel Research. 2017;133:181-91.

[29] CEN. EN 10149-2:2013. Hot rolled flat products made of high yield strength steels for cold forming. Part 2: Technical delivery conditions for thermomechanically rolled steels. 2013.

[30] Arcelormittal. Amstrong - High Strength Steels. http://industry.arcelormittal.com/catalogue/A20/EN. 2018.

[31] RFCS Project DuraMech, Towards best practice for bolted connections in high strength steels

[32] Denys K, Coppieters S, Seefeldt M, Debruyne D. Multi-DIC setup for the identification of a 3D anisotropic yield surface of thick high strength steel using a double perforated specimen. Mechanics of Materials. 2016;100:96-108.

[33] CEN. EN 1993-1-8. Eurocode 3: design of steel structures - Part 1-8: Design of joints. Brussels2005.

[34] Sánchez L, Gutiérrez-Solana F, Pesquera D. Fatigue behaviour of punched structural plates. Engineering Failure Analysis. 2004;11:751-64. 
[35] Garcia T, Cicero S, Ibáñez FT, Álvarez JA, Martín-Meizoso A, Bannister A, et al. Fatigue Performance of Thermally Cut Bolt Holes in Structural Steel S460M. Procedia Engineering. 2015;133:590-602.

[36] Cai J, Dean TA, Hu ZM. Alternative die designs in net-shape forging of gears. Journal of Materials Processing Technology. 2004;150:48-55.

[37] Kalpakjian S, Schmid SR. Manufacturing engineering and technology: Pearson Upper Saddle River, NJ, USA; 2014.

[38] VariDrillTM Catalogue. 2017.

[39] Freton P, Gonzalez J, Gleizes A, Peyret FC, Caillibotte G, Delzenne M. Numerical and experimental study of a plasma cutting torch. Journal of Physics D: Applied Physics. 2001;35:115.

[40] Jezernik N, Glodež S, Vuherer T, Špes B, Kramberger J. The influence of plasma cutting process on the fatigue strength of high strength steel S960Q. Key Engineering Materials: Trans Tech Publ; 2007. p. 669-72.

[41] ISO. 6507-1: 2018 Metallic materials -- Vickers hardness test -- Part 1: Test method. 2018. [42] García T, Cicero S, Álvarez JA. Justification of fatigue test with stress R-ratio=0.1. HIPERCUT deliverable. Santander2014.

[43] Thomas DJ. Characteristics of abrasive waterjet cut-edges and the affect on formability and fatigue performance of high strength steels. Journal of Manufacturing Processes. 2009;11:97-105.

[44] Gvozdev A, Sergeyev N, Minayev I, Kolmakov A, Tikhonova I, Sergeyev A, et al. Temperature distribution and structure in the heat-affected zone for steel sheets after laser cutting. Inorganic materials: Applied Research. 2017;8:148-52.

[45] Zöltzer G, Altenberger I, Scholtes B. Einfluss von Eigenspannungen auf die Mikrohärteverteilung in elastisch-plastisch gebogenen Stäben aus C80. HTM Härterei-technische Mitteilungen. 2001;56:347-52. 